\title{
Microbial dynamics during azo dye degradation in a UASB reactor supplied with yeast extract
}

\author{
S.Q. Silva ${ }^{1}$, D.C. Silva ${ }^{1}$, M.C.S. Lanna ${ }^{1}$, B.E.L. Baeta ${ }^{2}$, S.F. Aquino ${ }^{2}$ \\ ${ }^{1}$ Laboratório de Biologia e Tecnologia de Micro-organismos, Departamento de Ciências Biológicas, \\ Universidade Federal de Ouro Preto, Ouro Preto, MG, Brazil. \\ ${ }^{2}$ Laboratório de Controle Ambiental, Departamento de Química, Universidade Federal de Ouro Preto, \\ Ouro Preto, MG, Brazil.
}

Submitted: April 23, 2012; Approved: June 6, 2014.

\begin{abstract}
The present work aimed to investigate the microbial dynamics during the anaerobic treatment of the azo dye blue HRFL in bench scale upflow anaerobic sludge bed (UASB) reactor operated at ambient temperature. Sludge samples were collected under distinct operational phases, when the reactor were stable (low variation of color removal), to assess the effect of glucose and yeast extract as source of carbon and redox mediators, respectively. Reactors performance was evaluated based on COD (chemical oxygen demand) and color removal. The microbial dynamics were investigated by PCR-DGGE (Polimerase Chain Reaction - Denaturing Gradient of Gel Electrophoresis) technique by comparing the $16 \mathrm{~S}$ rDNA profiles among samples. The results suggest that the composition of microorganisms changed from the beginning to the end of the reactor operation, probably in response to the presence of azo dye and/or its degradation byproducts. Despite the highest efficiency of color removal was observed in the presence of $500 \mathrm{mg} / \mathrm{L}$ of yeast extract (up to $93 \%$ ), there were no differences regarding the microbial profiles that could indicate a microbial selection by the yeast extract addition. On the other hand Methosarcina barkeri was detected only in the end of operation when the best efficiencies on color removal occurred. Nevertheless the biomass selection observed in the last stages of UASB operation is probably a result of the washout of the sludge in response of accumulation of aromatic amines which led to tolerant and very active biomass that contributed to high efficiencies on color removal.
\end{abstract}

Key words: azo dye, UASB reactor, PCR-DGGE, wastewater treatment; microbial profile.

\section{Introduction}

Azo dyes represent the major group of dyes normally used in the textile industry, however such compounds cause environmental concern because of their color, biorecalcitrance and potential toxicity to aquatic organisms and humans (Cervantes and Santos, 2011). Textile effluents can be treated by a variety of processes that includes biological and physical-chemical schemes, and one technology that has the potential of being used for color removal of textile effluents is the anaerobic digestion (Georgiou et al., 2004; Baeta et al., 2012). In anaerobic conditions, textile pollutants such as the azo dyes can be used as electron acceptors, leading to the reduction of the azo bond $(-\mathrm{N}=\mathrm{N}-)$ and production of amines, mostly aromatic. Indeed, different research groups have demonstrated that removal efficiencies varying from 60 to $80 \%$ can be obtained during the anaerobic treatment of azo dye solutions (Mendez-Paz et al., 2005; dos Santos et al., 2006a).

Anaerobic reduction of azo bond is a reaction between enzymatic cofactors and the dye, and this is believed to be an extra-cellular process which depends on the redox potential of the solution and the dye (Pandey and Iyengar, 2007). External carbon sources favors the degradation rate and provides the electrons used in the production of the reduced compounds. The kinetics of azo dye reduction de- 
pends on the dye concentration and on the presence of reducing equivalents, both in the presence of external carbon sources and redox mediators, no matter if it is used a single microorganism or a consortium (Willets and Ashbolt, 2000). Several redox mediators have been shown to be important on the anaerobic azo dye degradation (Rafii et al., 1990; Nigam et al., 1996), and a work carried out in our laboratory (Correa et al., 2009) showed that yeast extract accelerated the kinetics of anaerobic decolorization of HFRL azo dye solutions probably because it was a source of riboflavin, a known redox mediator.

Microbial decolorization requires an unspecific enzymatic capacity ubiquitously found in a wide diversity of microorganisms. For instance, there are azoreductase enzymes that catalize the reaction of azo dye reduction. Rafii et al. (1990) isolated several strains of anaerobic bacteria (identified as species of the genera Eubacterium, Butyrivibrio and Bacteroides) capable of reducing the azo dye Direct Blue 15 in the presence of flavin compound (riboflavin, flavin adenine dinucleotide, or flavin mononucleotide) for the azoreductase activity. Another isolate however, Clostridium perfringens did not require flavin compound for azo dye reduction. According to the authors at least three types of azoreductase enzymes were produced by the different isolates and released extracellularly (Rafii et al., 1990).

According to dos Santos et al. (2006b) it is currently accepted that azo dye reduction occurs due to a cometabolic reaction, in which the biologically formed reducing equivalents can be chemically transferred to the azo dyes. In anaerobic consortia, reducing equivalents are formed by fermentative bacteria, and the methanogens consume these reducing equivalents to produce methane. However, it might be as well that some methanogens conduct the reducing equivalents towards dye reduction instead of methanogenesis (dos Santos et al., 2006b). In this way, fermentative bacteria and methanogenic archaea would play an important role in the reduction of azo dyes, but little is known about these microbial aspects of anaerobic consortia sampled from biological reactors employed for reductive azo dye removal.

The molecular technique based on polymerase chain reaction followed by denaturing gradient gel electrophoresis technique (PCR-DGGE) (Muyzer et al., 1993) is a well-known technique applied to investigate microbial dynamics in natural and engineered environments, including anaerobic bioreactors applied to azo dye treatment. For instance, Tan et al. (2010) used PCR-DGGE technique to show that not only the stability but also the adequate dynamics and diversity of the microbial community structure are important for the stable performance of a sequencing batch reactor (SBR) treating hyper-saline azo dye wastewater.

The main objective of this study was to investigate the microbial community dynamics in bench scale UASB reactor employed for azo dye degradation in response of glucose and yeast extract addition as source of carbon and redox mediator, respectively.

\section{Materials and Methods}

\section{Experimental apparatus}

A bench scale UASB reactor was built using polyvinyl chloride (PVC) pipes and joints and had a total working volume of $8 \mathrm{~L}$. The upper settler was $250 \mathrm{~mm}$ height and had $150 \mathrm{~mm}$ of diameter, making up $2 \mathrm{~L}$ of the working volume, whereas the digestion chamber had $100 \mathrm{~mm}$ of diameter and $800 \mathrm{~mm}$ of height. The reactor project followed the parameters recommended by Chernicharo (2007) and resulted in average hydraulic volumetric load and upflow velocity in the digestion chamber of, respectively, $1.3 \mathrm{~m}^{3} / \mathrm{m}^{3}$.d and $0.0165 \mathrm{~m} / \mathrm{h}$. Such low upflow velocity contributed for nearly complete retention of solids in the UASB reactor.

The bench scale reactor was incubated with anaerobic sludge from a demo scale UASB reactor installed at the Centre for Research and Training on Sanitation (CePTS) UFMG/COPASA, located at the Arrudas WWTP, in Belo Horizonte - Brazil. The bench scale UASB was operated at ambient temperature and under different conditions (Table 1). In all phases the hydraulic retention time (HRT) was kept at $19 \mathrm{~h}$ and the reactor was run without any discharge of biomass, except during sampling for physical-chemical analyses.

The feed solution was comprised of glucose (except in phase 4 and 8), blue HRFL azo dye (except in phase 1 and 6), yeast extract (except phases 1, 2, 6 and 7) and macronutrient solution, which composition is described elsewhere (Aquino and Stuckey, 2007). In all phases, the minimum COD:N:P proportion of 350:5:1 was observed, according to Chernicharo (2007). The feeding recipient $(20 \mathrm{~L})$ was filled up twice a day with freshly prepared influent solution to minimize the growth of microorganisms and

Table 1 - Operational conditions applied to the UASB reactor for azo dye degradation.

\begin{tabular}{lcccc}
\hline $\begin{array}{l}\text { Operational } \\
\text { phases }\end{array}$ & $\begin{array}{c}\text { Time of } \\
\text { operation*(d) }\end{array}$ & $\begin{array}{c}\text { Glucose } \\
(\mathrm{mg} / \mathrm{L})\end{array}$ & $\begin{array}{c}\text { Blue HFRL } \\
\text { dye(mg/L) }\end{array}$ & $\begin{array}{c}\text { Yeast extract } \\
(\mathrm{mg} / \mathrm{L})\end{array}$ \\
\hline P1 & 10 & 500 & - & - \\
P2 & 14 & 450 & 50 & - \\
P3 & 13 & 350 & 50 & 100 \\
P4 & 14 & - & 50 & 100 \\
P5 & 14 & 350 & 50 & 500 \\
P6 & 17 & 500 & - & - \\
P7 & 15 & 450 & 50 & - \\
P8 & 13 & - & 50 & 500 \\
\hline
\end{tabular}

*Days counted after the reactor had reached stability, based on low variation of color removal. 
consequent removal of COD and color in the feeding line. The feed was pumped into the reactor by means of a peristaltic pump (Dosa Mini 400, HD Hidraulics) at constant flow rate, calculated to maintain the desired hydraulic retention time (HRT).

\section{Chemical analysis}

COD analyses in influent and effluent samples and total solids (TS) analysis in the sludge collected inside the UASB digestion chamber were carried out according to the Standard Methods for the Examination of Water and Wastewater (APHA, 2005). The efficiency of color removal was assessed by following the absorbance of the centrifuged solution in a spectrophotometer (HP 8453 UV-Visible system). For this it was selected an wavelength $(\lambda$ máx $=654 \mathrm{~nm})$ in which the azo dye blue HFRL exhibited maximum absorbance. The volatile fatty acids (VFA) concentration was determined as described elsewhere (Mesquita et al., 2010), and the COD due to such compounds were calculated from stoichiometric coefficients as reported elsewhere (Aquino and Stuckey, 2007). All analysis were done in duplicate.

\section{PCR-DGGE analysis}

Sludge samples taken from the UASB reactor at the end of all operational phases (P1 to P8) were submitted to the PCR-DGGE analysis. First genomic DNA was extracted from the sludge by the phenol-chloroform method (Griffiths et al., 2000) followed by amplification of $16 \mathrm{~S}$ rRNA sequences using the DGGE universal bacterial primers 968F-GC and 1392R (Nielsen et al., 1999) and archaeal primers 1100F-GC and 1400R (Kudo et al., 1997). Each PCR reaction was performed with $2.5 \mu \mathrm{L}$ reaction buffer (10 mM KCl, $20 \mathrm{mM}$ Tris-HCl [pH 8.8], Fermentas); $2.0 \mu \mathrm{L} \mathrm{MgCl}_{2}$ (25 mM, Fermentas); $1.25 \mu \mathrm{L}$ of each primer (10 pmol $/ \mu \mathrm{L}$, Bioneer); $0.5 \mu \mathrm{L}$ dNTP's $(10 \mathrm{mM}$, Fermentas); $1.0 \mu \mathrm{L}$ of BSA (Bovine Serum Albumin $5 \mathrm{mg} / \mathrm{L}$, Fermentas); $0.1 \mu \mathrm{L}$ Taq polymerase $(5 \mu / \mu \mathrm{L}$, Fermentas); $0.5-1.0 \mu \mathrm{L}$ DNA template in a total volume of $25 \mu \mathrm{L}$. The PCR reactions were performed in Automatic Termocycler Biocycler TM MJ96+. For bacterial amplification the PCR cycling parameters included an initial denaturation at $94{ }^{\circ} \mathrm{C}$ for $3 \mathrm{~min}$, followed by 30 cycles of denaturation at $94{ }^{\circ} \mathrm{C}$ for $1 \mathrm{~min}$, annealing at $55{ }^{\circ} \mathrm{C}$ for 2 min and extension at $72{ }^{\circ} \mathrm{C}$ for $2 \mathrm{~min}$ and final extension of $20 \mathrm{~min}$ at $72^{\circ} \mathrm{C}$. For archaeal amplification an initial denaturation at $94^{\circ} \mathrm{C}$ for $3 \mathrm{~min}$, followed by 35 cycles of denaturation at $94^{\circ} \mathrm{C}$ for $30 \mathrm{~s}$, annealing at $55^{\circ} \mathrm{C}$ for $30 \mathrm{~s}$ and extension at $72^{\circ} \mathrm{C}$ for $1 \mathrm{~min}$ and final extension of $15 \mathrm{~min}$ at $72 \mathrm{vC}$. The amplified fragments were analyzed on agarose gel $1 \%(\mathrm{w} / \mathrm{v})$ in $1 \mathrm{x}$ TAE buffer $(0.04 \mathrm{M}$ Tris-acetate, 0.001 M EDTA) for $30 \mathrm{~min}$ at $100 \mathrm{~V}$, stained with DNA Gel Stain Syber Safe ${ }^{\circledR}$ (Invitrogen) and visualized in a transiluminator under UV light.
The electrophoretic separation of DNA fragments was performed in a DGGE apparatus (DGGE-1001, C.B.S., Scientific Company, INC., USA, Laboratory of Hydrometallurgy, University of Ouro Preto). For the Bacteria domain a bis-acrylamide gel $6 \%(\mathrm{w} / \mathrm{v})$ with a denaturing gradient of urea-formamide between $40 \%-60 \%$ for bacterial domain and 35\%-55\% for Archaea domain. A volume of $20 \mu \mathrm{L}$ of each PCR products was loaded on the gel and the electrophoresis were performed at $100 \mathrm{~V}$ for $16 \mathrm{~h}$ at $60{ }^{\circ} \mathrm{C}$. The gels were then stained in ethidium bromide solution for $60 \mathrm{~min}$ and visualized under UV light. DGGE profiles were compared with regard to the presence or absence of bands, using the Jaccard dissimilarity coefficient and constructing a dendrogram in SYN-TAX Program (NCLS - ver Jan00).

The DNA sequencing of the reverse DNA strands were performed using BigDye ${ }^{\circledR}$ Terminator v3.1 Cycle Sequencing (Applied Biosystems) by Genomic Engenharia Molecular (São Paulo, Brazil). Sequences were further aligned using Jukes-Cantor model with several 16S rRNA sequences available in the RDP-10 (Ribossomal Database Project, Release 10 (Cole et al., 2009)). Phylogenetic tree containing the isolate sequence as well as the closest sequences from the database was constructed by the method of Neighbor Joining with bootstrap analysis of 1,000 replicates in Mega 4 software (Tamura et al., 2007). The sequences determined here for archaeal DGGE bands have been deposited in GenBank under accession numbers JN692487 to JN692492.

\section{Results and Discussion}

\section{Performance of UASB reactor for azo dye decolorization}

The results obtained from the bioreactors monitoring is presented in Table 2. According to the results, the best efficiency on color removal was observed in P5, when the reactor was fed with glucose and yeast extract, and also in the last operational phase, $\mathrm{P} 8$, when reactor was fed only with $500 \mathrm{mg} / \mathrm{L}$ of yeast extract. The difference observed between P5 and P8 in terms of COD removal (higher for P8) is probably due to the addition of $350 \mathrm{mg} / \mathrm{L}$ of glucose to the influent which increased the organic load in the reactor and led to the accumulation of intermediate organic acids, as indicated by the highest value of $\mathrm{COD}_{\mathrm{VFA}}$ at P5 as presented in the Table 2.

Yeast extract is a rich source of nutrient including carbon sources and vitamins which enhance the growth of several bacterial. Vitamin B12 (or riboflavin) and niacin are enzymatic cofactors present in the yeast extract which can therefore be used by microorganisms (Leclerc et al., 1998). The high color removal efficiencies observed when yeast extract was present in the influent (see phase 5, Table 2) suggest that this compound favored the reductive degradation of blue HRFL azo dye, probably because it 
Table 2 - Average values of color and COD removal efficiency, and TS and $\mathrm{COD}_{\mathrm{VFA}}$ concentration in the UASB reactor in different operational phases.

\begin{tabular}{|c|c|c|c|c|c|c|c|c|}
\hline & $\mathrm{P} 1(\mathrm{n}=7)$ & $\mathrm{P} 2(\mathrm{n}=11)$ & P3 $(n=10)$ & $\mathrm{P} 4(\mathrm{n}=10)$ & P5 $(n=12)$ & P6 $(n=9)$ & $\mathrm{P} 7(\mathrm{n}=8)$ & $\mathrm{P} 8(\mathrm{n}=10)$ \\
\hline Color Removal Efficiency (\%) & - & $65 \pm 7$ & $64 \pm 4$ & $54 \pm 6$ & $93 \pm 3$ & - & $62 \pm 6$ & $91 \pm 1$ \\
\hline COD Removal Efficiency (\%) & $24 \pm 5$ & $43 \pm 11$ & $44 \pm 25$ & 0 & $40 \pm 15$ & $49 \pm 4$ & $61 \pm 7$ & $54 \pm 4$ \\
\hline Total Solids (digestion chamber) (g) & $60 \pm 4.0$ & $65 \pm 6.1$ & $42 \pm 7.8$ & $20 \pm 3.1$ & $40 \pm 3.2$ & $40 \pm 2.9$ & $40 \pm 3.5$ & $10 \pm 0.8$ \\
\hline $\mathrm{COD}_{\mathrm{VFA}}(\mathrm{mg} / \mathrm{L})$ & - & $55 \pm 12$ & $210 \pm 63$ & - & $322 \pm 103$ & $201 \pm 43$ & $87 \pm 15$ & $86 \pm 18$ \\
\hline
\end{tabular}

\pm standard deviation, -not measured.

acted as source of redox mediator (e.g. riboflavin and niacin) which accelerates the transfer of biologically generated reducing equivalents to the azo dye. Besides providing redox mediators, yeast extract can also be source of carbon and energy. Indeed, Table 2 shows that high color removal rates was observed in phase 8 , indicating that in the presence of yeast extract an extra carbon source, such as glucose, can be omitted during the anaerobic treatment of the azo dye. Similar results were obtained by Leclerc et al. (1998) in which bacterial growth and decolorization in the medium supplemented with yeast extract was higher than when glucose was added. However according to the authors, the culture grew primarily on the yeast extract, producing sufficient biomass which then was able to reduce azo dyes to the corresponding amines, thus leading to color removal.

Table 3 presents the specific rate of COD and color removal considering the biomass present in the reactor. It can be seen that phase 8 exhibited the highest specific decolorization rate $(\sim 19.6 \mathrm{~g}$ Dye/kg TS.d) and the second highest COD removal (127.4 g COD/kg TS.d) despite the fact that in this phase there was the lowest amount of total solids, meaning biomass, inside the reactor. This indicates that the continuous operation of the bioreactor, for over 3 months, led to the predominance of a very active biomass.

\section{Shifts on microbial community structure during the anaerobic azo dye degradation}

DGGE fingerprints regarded to Bacteria and Archaea domains are presented on Figure 1. In order to get better information regarded to the similarities among samples a dendogram was constructed and it is shown on Figure 2. According to the Figure 2a, it can be inferred that the bacterial community changed along the operational phases considering the highest level of difference between P1 and P8.
Considering the $\mathrm{P} 1$ and $\mathrm{P} 2$ profiles it can be seen that the addition of azo dye to the reactor caused a considerable shift on the bacterial community whereas the yeast extract addition seemed no to cause significant changes (P3 and $\mathrm{P5}$ ) compared with the community established before (P2 and $\mathrm{P} 4)$. Therefore the predominant bacterial groups did not change considerably after the addition of yeast extract despite the best results for color removal observed in phase 5 (Table 2). It was believed that the addition of yeast extract could lead to a biomass selection towards those more dependent on the nutrients present in the compound, however this was not observed. According to Leclerc et al. (1998) vitamins provided by yeast extract were shown to be essential cofactors of the reductive pathway of acetate synthesis of several fermentative acetogenic bacteria. Concentration of yeast extract higher than 1-2 g/L showed a stimulatory effect on the autotrophic metabolism of acetogenic bacteria (homoacetogenesis, via $\mathrm{H}_{2} / \mathrm{CO}_{2}$ ) rather than the heterotrophic one (Leclerc et al., 1998). Therefore it could be inferred that the yeast extract applied here $(500 \mathrm{mg} / \mathrm{L})$ was not the selection pressure that prompted shifts in the predominant bacterial community or neither in the oxidative/reductive pathway of acetogenic microorganisms.

It can be seen on Figure 1 that the band intensities were stronger in P5 indicating an increase on bacterial and archaeal cells probably due to the 5-fold increase on the yeast extract concentration when compared to phase 1 .

According to the DGGE results, the archaeal profiles were clustered into four groups (Figure 2b). The first group includes sample from $\mathrm{P} 1$ to $\mathrm{P} 4$, in which it is observed the highest similarity among samples. This suggests that the addition of azo dye and yeast extract did not promote shifts on the predominant archaeal community. Only in the final stages of operation (from P6 to P8) when the highest con-

Table 3 - Specific rates of COD consumption and azo dye removal in the UASB reactor in different operational phases.

\begin{tabular}{|c|c|c|c|c|c|c|c|c|}
\hline & $\mathrm{P} 1(\mathrm{n}=7)$ & $\mathrm{P} 2(\mathrm{n}=11)$ & P3 $(n=10)$ & $\mathrm{P} 4(\mathrm{n}=10)$ & P5 $(n=12)$ & P6 $(n=9)$ & $\mathrm{P} 7(\mathrm{n}=8)$ & P8 $(n=10)$ \\
\hline $\begin{array}{l}\text { Specific rate on COD } \\
\text { consumption }(\mathrm{g} / \mathrm{kg} \cdot \mathrm{d})\end{array}$ & $18.5 \pm 3.7$ & $39.1 \pm 9.7$ & $43.7 \pm 24$ & 0 & $132.6 \pm 49$ & $78.8 \pm 7.8$ & $95.1 \pm 10.8$ & $127.4 \pm 8.9$ \\
\hline $\begin{array}{l}\text { Specific rate on } \\
\text { decolorization }(\mathrm{g} / \mathrm{kg} . \mathrm{d})\end{array}$ & - & $5.3 \pm 0.6$ & $6.0 \pm 0.4$ & $9.0 \pm 0.9$ & $16.7 \pm 0.5$ & - & $8.3 \pm 0.8$ & $19.6 \pm 0.2$ \\
\hline
\end{tabular}

\pm standard deviation. 

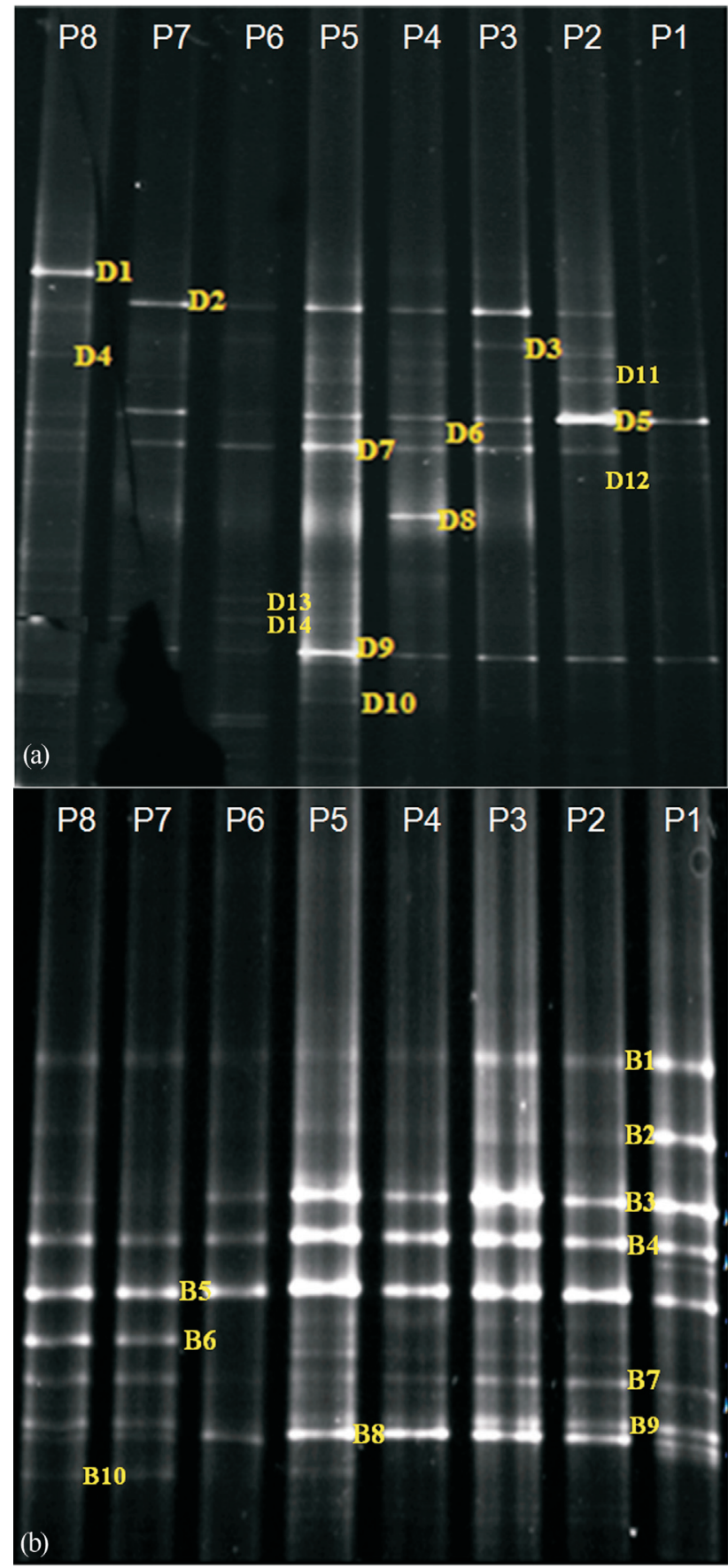

Figure 1 - DGGE fingerprint of sludge samples based on the eletrophoretic mobility of $16 \mathrm{~S}$ rDNA sequences. a) bacterial sequences amplified by primers $968 \mathrm{~F}-\mathrm{GC} / 1392 \mathrm{R}$ on a denaturing gradient of $40 \%-60 \%$. b) archaeal sequences amplified by primers $1100 \mathrm{~F}-\mathrm{GC} / 1400 \mathrm{R}$ on a denaturing gradient of $35 \%-55 \%$. Legend: P1 to P8: operational phases (see Table 1); D1 to D10 selected bacterial bands; B1 to B8 selected archaeal bands.

centration of yeast extract was applied a small change was observed. This was probably a result of the enrichment promoted by the added organic substrates, which during the anaerobic degradation generates $\mathrm{H}_{2}, \mathrm{CO}_{2}$ and acetate which are substrates for methane production.
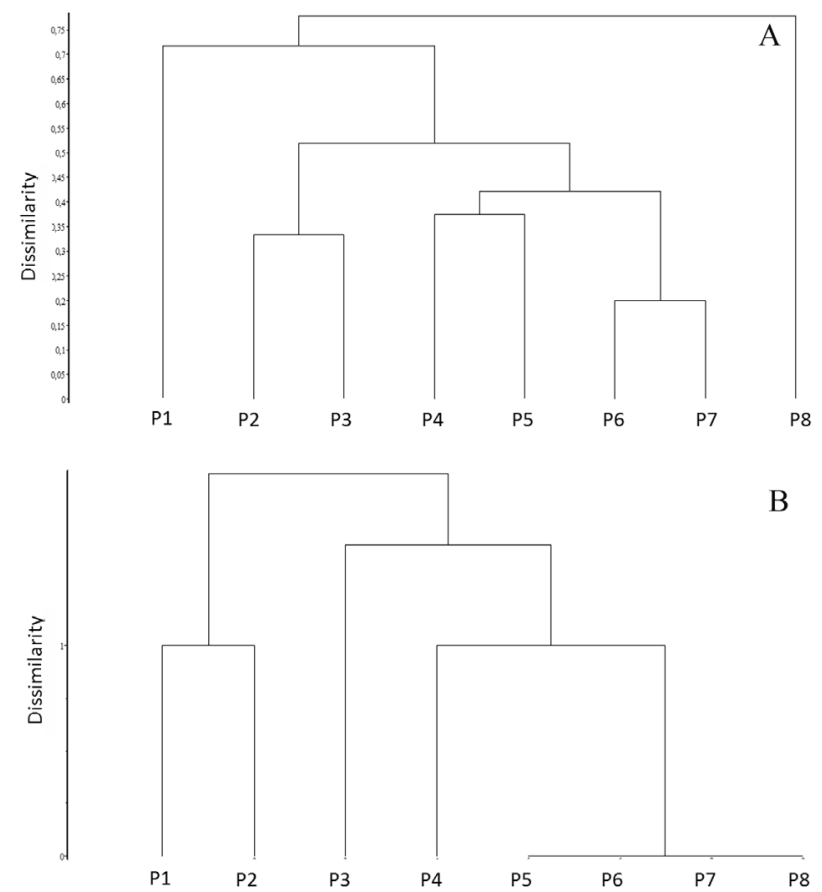

Figure 2 - Dendograms based on DGGE profiles using the Jaccard dissimilarity coefficient constructed in SYN-TAX Program. a) dissimilarity among bacterial DGGE profiles during the reactor operation. $\mathrm{b}$ ) dissimilarity among archaeal DGGE profiles during the reactor operation.

Because of the lost of total solids (Table 2) the reactor was fed only with glucose during P6 in order to reestablish the biomass concentration, and this seemed to have resulted in significant changes in microbial composition in terms of number and position of bands. Considering the bacterial results, more bands in different positions appeared in the operational phase 7 , including band D8 with a strong intensity, indicating that a more diverse, and probably more adapted bacterial biomass, was present at the last stage of UASB operation. Similar observation can be made for archaeal community for phase 7 and 8 , since the changes in the profiles includes the presence of bands that were not visualized in the previous phases.

However the differences between P8 and other samples for the bacterial profile (Figure 2a) suggest that in this phase a selection pressure on the microbial community occurred, maybe as a result of the increased azo dye degradation byproducts (e.g. aromatic amines). According to DGGE and TS results, the lost of solids in phase 8 suggests that some microbial groups, probably those less adapted, were washed out of the reactor, leaving a more adapted biomass which, despite being in lower amount, was efficient to maintain the high efficiencies of COD and color removal (Table 3). Tan et al. (2010) applied PCR-DGGE technique and also showed that an adequate dynamics and diversity of the microbial community structure are important for the stable performance of a bioreactor applied for anaerobic azo dye treatment. 
Despite no bacterial bands were identified, it can be assumed that fermentative bacteria were present in the UASB sludge since this group play an important role as intermediated microorganisms during the anaerobic degradation of organic matter. Fermentative bacteria such species of Pseudomonas were shown to play an important role on decolorization process under anaerobic conditions (Bhatt et al., 2005; Kalyane et al., 2008). Therefore it can be hypothesized that a more adapted community of fermentative bacteria (e.g. tolerant to aromatic amines) were present in the anaerobic consortia at the last stages of UASB operation, and their presence is essential in supplying the reducing equivalents to accomplish azo dye reduction and/or methane production.

It seems that phases 7 and 8 favored the growth of archaeal cells, such as those represented by band B6, probably more adapted to the harsh in situ conditions. Sequencing results of 6 archaeal bands (B2, B3, B4, B5, B6 and B8) has shown high similarities with archaeal species, as presented in Figure 3. According to the phylogenetic analy- sis presented on Figure 3, the archaeal sequences were grouped in three clusters: Methanobacterium cluster (B8, B5 and B4), Methanosarcina cluster (B6) and Methanosaeta cluster (B3 and B2). In relation to the DGGE profiles, sequences belonging to Methanobacterium cluster were present in all phases of the UASB operation, indicating that the changes in the influent (presence/absence of azo dye, yeast extract or glucose) had little impact on the dynamics of these microorganisms. On the other hand, the Methanosarcina-B6 band was detected only in the last two operational phases (P7 and P8) of UASB reactor, whereas Methanosaeta-B3 and -B2 bands were only barely visualized in these samples. Such observation suggests a change in the community of archaea regarding the aceticlastic methanogens, dominated by Methanosaeta (mainly B3) during the early phases, but which was further replaced by Methanosarcina specie (B6).

The dynamics of Methanosaeta and Methanosarcina is well known and acetate concentration seems to be the driving force that controls the dominance of one group over

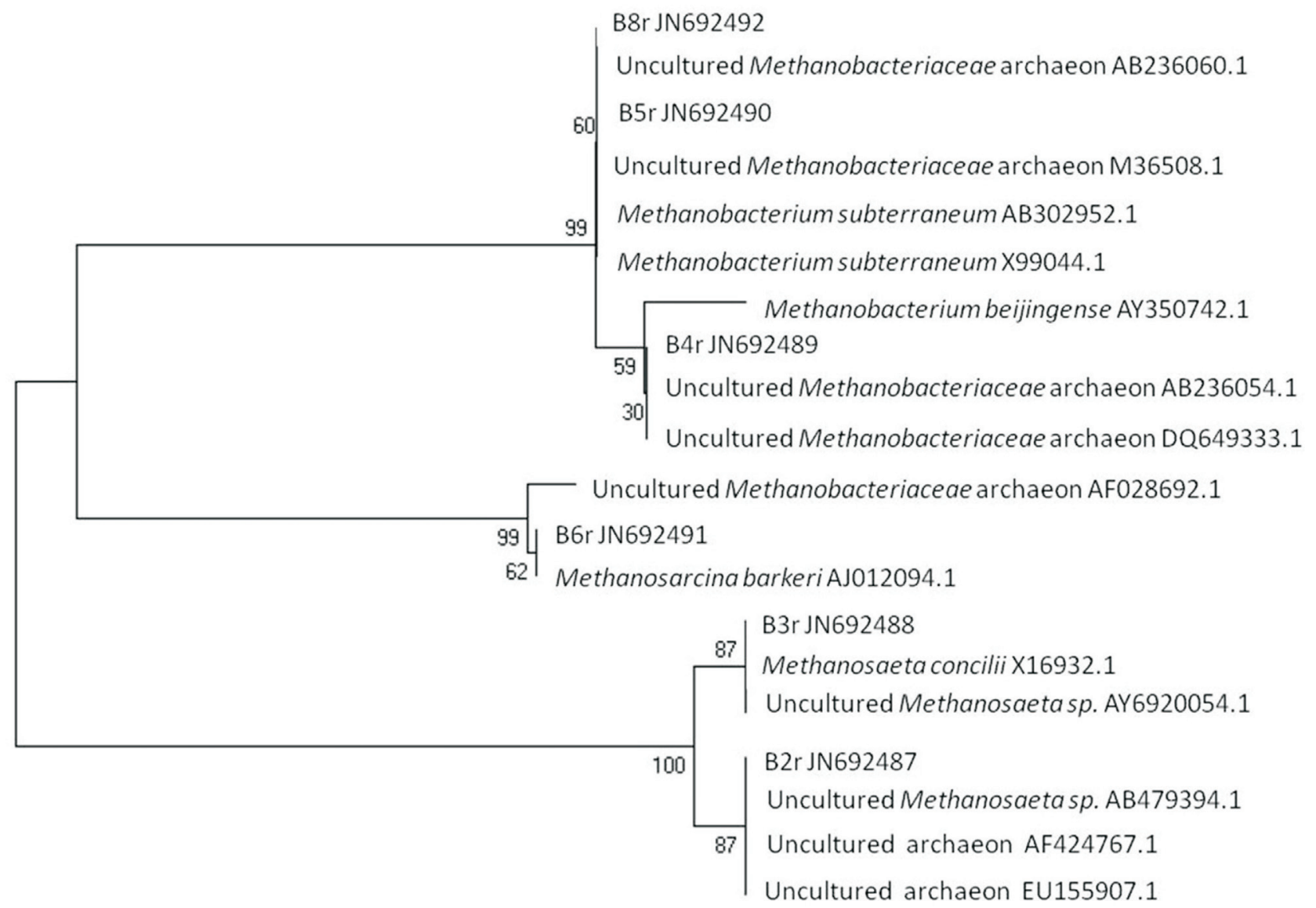

$\longmapsto .01$

Figure 3 - Neighbor Joining phylogenetic tree containing archaeal 16S from DGGE bands as well as the closest sequences from the RDP-10 database. Bar $=1.0 \%$ estimated phylogenetic divergence. The bootstrap support (1,000 replicates) values are shown at nodes. All sequences ( $\sim 300$ bp) were aligned using Jukes-Cantor model and phylogenetically analysed in Mega 4 software. 
the other in anaerobic bioreactors. Methanosarcina appears to be a generalist with a high growth rate and low affinity for acetate (threshold for acetate between 200 a 1,220 $\mu \mathrm{M}$ or 16 and $100 \mathrm{mg} / \mathrm{L}$ ) (Jetten et al., 1992). On the other hand, Methanosaeta is a specialist having a high affinity for acetate (threshold for acetate between 7 and $70 \mu \mathrm{M}$ or 0.6 and $6 \mathrm{mg} / \mathrm{L}$ ), but low growth rate (13). The COD $\mathrm{VFA}$ values (Table 2) during the operation suggest that some accumulation of volatile fatty acids (mainly acetic acid, result not shown) occurred. Despite the $\mathrm{COD}_{\mathrm{VFA}}$ values were in the range for favoring Methanosarcina, the Methanosarcina barkeri was only detected at P7 and P8 compared with the others phases. Therefore other selection pressure may have occurred to favor this specie at the last stages of the reactors operation.

Another interesting aspect regarding the methanogens is related to their role on the decolorization process. Although the specific role of methanogenic archaea in the reductive decolorization of azo dyes has not been fully elucidated, there are some evidences that they play a major role considering that high decolorization efficiencies have been related with high biogas productions in anaerobic bioreactors (Cervantes and dos Santos, 2011).

According to dos Santos et al. (2006b) the anaerobic azo dye reduction does not seem to be a universal property among methanogenic archaea, so that redox mediators might improve reductive decolorization by allowing some microbial groups commonly found in wastewater treatment systems to participate more effectively. For instance, Methanobacterium NJ1 and Methanosarcina barkeri were able to decolorize reactive red 2 (RR2) with hydrogen as an electron donor in axenic cultures under thermophilic conditions. However, whereas Methanobacterium NJ1 was able to reduce the azo dye only in the presence of riboflavin, Methanosarcina barkerii did not require it (dos Santos et al., 2006b). In the present work, the Methanobacterium-B5 and -B4 were apparently equally distributed along the UASB operation and did not respond to changes in the influent composition. In contrast, Methanosarcina barkeri-B6 band predominated in the last two phases of the UASB operation, indicating that if they are involved directly on the decolorization process, their activity is not dependent on riboflavin (added here as yeast extract), as showed by dos Santos et al. (2006b).

\section{Conclusions}

The microbial community developed in the UASB reactor fed with the azo dye HFRL responded to the presence of such compound changing from the beginning to the end of the reactor operation. The changes observed suggest a high degree of biomass adaptation, which is supported by the gradual increase on the specific rate of decolorization as the time of operation went by. The increase on color removal was positively associated with the presence of 500 $\mathrm{mg} / \mathrm{L}$ of yeast extract (source of riboflavin), but according to DGGE profiles the presence of this compound did not lead to the selection of particular group of microorganisms. The observed adaptation of biomass seemed to be a response of contact, for 110 days, with the azo dye and its degradation by products (e.g. aromatic amines). Such a selection pressure may have favoured the development of Methanosarcina barkerii in the reactor, probably acting as a decolorization agent which does not depend on riboflavin (added here as yeast extract). The color removal in the UASB reactor is likely to occur due to an association among adapted fermentative anaerobic bacteria and methanogenic archaea. Whereas bacteria produces reducing equivalents for the extracellular reduction of the azo dye, which is faster in the presence of yeast extract, some of the archaea population may act directly on the reduction of the azo dye bond without influence of redox mediators.

\section{Acknowledgments}

The authors would like to acknowledge the support they received from the following Brazilian agencies: Coordenação de Aperfeiçoamento de Pessoal de Nível Superior (CAPES), Conselho Nacional de Desenvolvimento Científico e Tecnológico (CNPq) and Fundação de Amparo à Pesquisa do Estado de Minas Gerais (FAPEMIG).

\section{References}

APHA. (2005) Standard Methods for the Examination of Water and Wastewater. $21^{\text {st }}$ Edition. American Public Health Association, Washington, DC.

Aquino SF and Stuckey DC (2007) Bioavailability and toxicity of metal nutrients during anaerobic digestion. J Environ Eng 133:28-35.

Baêta BEL, Aquino SF, Silva SQ, Rabelo CA (2012) Anaerobic degradation of azo dye Drimaren blue HFRL in UASB reactor in the presence of yeast extract a source of carbon and redox mediator. Biodegradation 23:199-208.

Bhatt N, Patel KC, Keharia H, Madamwar D (2005) Decolorization of diazo dye reactive blue 172 by Pseudomonas aeruginosa. J Basic Microbiol 45:407-418.

Cervantes FJ and dos Santos AB (2011) Reduction of azo dyes by anaerobic bacteria: Microbiological and biochemical aspects. Rev Environ Sci Biotechnol 10:125-137.

Chernicharo CAL (2007) Princípios do tratamento biológico de águas residuárias - Reatores Anaeróbios, Editora UFMG, Belo Horizonte.

Cole JR, Wang Q, Cardenas E, Fish J, Chai B, Darris RJ, KulamSyed-Mohideen AS, McgGarrel D, Marsh T, Garrity GM, Tiedje JM (2009) The Ribosomal Database Project: improved alignments and new tools for rRNA analysis. Nucleic Acids Research 37:141-145.

Correa CAR, Aquino SF, Caldas PCP, Silva SQ (2009) Uso do extrato de levedura, como fonte de carbono e mediadores redox, para a degradação anaeróbia de corante azo. Eng Sanit Ambient 14:559-568.

Dos Santos AB, Cervantes FJ, Van Lier JB (2006a) Potentials of high-temperature anaerobic treatment and redox mediators 
for the reductive decolourisation of azo dyes from textile wastewaters. Water Sci and Technol 54:151-156.

Dos Santos AB, de Madrid MP, de Bok FAM, Stams AJM, Van Lier JB, Cervantes FJ (2006b) The contribution of fermentative bacteria and methanogenic archaea to azodye reduction by a thermophilic anaerobic consortium. Enzyme Microb Tech 39:38-46.

Georgiou D, Metallinou C, Aivasidis A, Voudrias E, Gimouhopoulos K. (2004) Decolorization of azo-reactive dyes and cotton-textile wastewater using anaerobic digestion and acetate-consuming bacteria. Biochemical Engineering Journal 19:75-79.

Griffiths RI, Whiteley AS, ODonnell AG, Bailey MJ (2000). Rapid method for coextraction DNA and RNA from natural environments for analysis of rbiossomal rDNA- and rRNAbased microbial community composition. Appl Environ Microbiol 66:5488-5491.

Jetten, MSM.; Stams A J M, Zehnder AJB (1992) Methanogenesis from acetate: a comparison of the acetate metabolism in Methanothrix soehngenii and Methanosarcina spp. FEMS Microbiol Rev 88:181-198.

Kalyani PS, Patil JP, Jadhav SP, Govindwar DC (2008) Biodegradation of reactive textile dye Red BLI by an isolated bacterium Pseudomonas sp. SUK1. Bioresource Technol 99:4635-4641.

Kudo Y, Nakajima T, Miyaki, T, Oyazu, H (1997) Methanogen flora of paddy soils in japan. FEMS Microb Ecol 22:39-48.

Leclerc M, Elfoul-Bensaid L, Bernalier A (1998) Effect of Yeast Extract on Growth and Metabolism of H2-Utilizing Acetogenic Bacteria from the Human Colon. Curr Microbiol 37:166-171.

Mendez-Paz D, Omil F, Lema JM (2005) Anaerobic treatment of azo dye Acid Orange 7 under batch conditions. Enzyme Microbiol Technol 36:264-272.
Mesquita PL, Aquino SF, Xavier ALP, Silva JC, Afonso RCF, Silva SQ (2010) Soluble microbial product (SMP) characterization in bench-scale aerobic and anaerobic CSTRs under different operational conditions. B J Chemical Engineering 27:101-111.

Muyzer G, Wall EC, Uitterlinden AG (1993) Profiling of complex microbial populations by denaturing gradient gel electrophoresis analysis of polymerase chain reaction-amplified genes coding for $16 \mathrm{~S}$ rRNA. Appl Environ Microbiol 59:695-700.

Nielsen TA, Liu WT, Filipe C, Grady L, Molin S, Stahl DA (1999) Identification of a novel group of bacteria in sludge froma deteriorated biological phosphorus removal reactor. Appl Environ Microbiol 65:1251-1258.

Nigam P, Banat IM, Singh D, Marchant R (1996) Microbial process for the decolorization of textile effluent containing azo, diazo and reactive dyes. Process Biochem 31:435-442.

Pandey AP and Iyengar SL (2007) Bacterial decolorization and degradation of azo dyes. International Biodeterioration and Biodegradation 59:73-84,

Rafii F, Franklin W, Cerniglia CE (1990) Azoreductase activity of anaerobic bacteria isolated from human intestinal microflora. Appl Environ Microbiol 56:2146-2151.

Tamura K, Dudley J, Neu M, Kumar S (2007) MEGA4: Molecular Evolutionary Genetics analysis (MEGA) software version 4.0. Molecular Biology and Evolution. 24:1596-1599.

Tan L, Yuanyuan Q, Zhou J, Ma F, Li A (2010) Microbial community shifts in sequencing batch reactors for azo dye treatment. Pure Applied Chemistry 82:299-306.

Willets JRM and Ashbolt NJ (2000) Understanding anaerobic decolourisation of textile dye wastewater: Mechanism and kinetics. Water Sci Technol 42:409-415.

All the content of the journal, except where otherwise noted, is licensed under a Creative Commons License CC BY-NC. 